\title{
Effect of the COVID-19 pandemic on CT scans ordered from the emergency department for abdominal complaints
}

\author{
April M. Griffith ${ }^{1}$ (D) $\cdot$ Patrick Ockerse $^{2} \cdot$ Akram Shaaban $^{1} \cdot$ Christopher Kelly $^{2}$
}

Received: 28 November 2020 / Accepted: 20 January 2021 / Published online: 30 January 2021

(C) American Society of Emergency Radiology 2021

\begin{abstract}
Purpose The COVID-19 pandemic has affected healthcare systems and patients alike across the USA. We seek to elucidate changes in abdominal imaging ordered from the emergency department (ED) in a healthcare system undergoing non-surge conditions in April 2020 compared to April 2019.

Methods We performed a retrospective, observational study comparing patients undergoing CT scans of the abdomen and pelvis ordered from the ED in April 2020 vs. April 2019 at a single healthcare center. Via review of the radiology report and electronic medical record, we determined the positive or negative status of these scans. We evaluated percentages of positive CT scans and differences in outcomes, including admission rates, interventions, and mortality.

Results Comparing 2020 to 2019, there was a $31.6 \%$ decrease in the number of CT scans performed from the ED. We found a higher percentage of positive CT findings, $58.2 \%$ vs. $50.8 \%(p=0.025)$, and increased admission rates, $40.8 \%$ vs. $34.1 \%(p=$ 0.036). Differences were found in rates of appendicitis, colitis, and cholangitis. No difference was found in ICU admissions, interventions, or in-hospital mortality.

Conclusion During the COVID-19 pandemic in a region undergoing non-surge conditions, we found increased rates of positive CT scans performed from the ED for abdominal complaints with an increased percentage of hospital admissions compared to a control year. No differences in ICU admissions or rates of procedural intervention were found to suggest higher acuity of pathology on presentation. Our findings suggest appropriately decreased healthcare utilization in our study period, driven by pre-hospital patient self-selection.
\end{abstract}

Keywords COVID-19 $\cdot$ Healthcare utilization $\cdot$ Emergency department $\cdot$ Computed tomography $\cdot$ Abdominal pain

\section{Introduction}

Throughout the COVID-19 pandemic, hospital systems across the United States of America (USA) have demonstrated marked alterations in patterns of patient visits and healthcare utilization [1-4], including for non-respiratory-related complaints [5]. This is true in both surge locations, in which strategies have been developed to address the immediate concern of limited resources, and in non-surge locations, in which

April M. Griffith

April.Griffith@hsc.utah.edu

1 Department of Radiology and Imaging Sciences, University of Utah Health, 30 North 1900 East \#1A071, Salt Lake City, UT 84132-2140, USA

2 Department of Surgery, Division of Emergency Medicine, University of Utah Health, Salt Lake City, UT, USA shelter-in-place orders, resource preservation strategies, and fear of contagion influence patient utilization of healthcare. The impact of such alterations in healthcare utilization is still under investigation.

Decreased emergency department (ED) visits are well documented across the USA, both in overall visits and specifically regarding non-respiratory complaints. For example, studies have shown decreased activations for numbers of STelevation myocardial infarctions [6], less acute stroke activations and evaluations $[7,8]$ —including notably fewer noncontrast-enhanced computed tomography (CT) scans of the head performed to evaluate for ischemic strokes [9] - and fewer presentations for traumatic pathology for orthopedic injuries [10,11]. Additionally, multiple studies demonstrate decreased pediatric visits in both surge and non-surge location [12-15].

Few studies have evaluated the impact of COVID-19 pandemic on presentations for abdominal complaints in the ED, 
and specifically the impact on positivity of CT findings, and none of which has been in the USA. Romero et al. reported data from their institution in Colombia suggesting that while there were fewer CT scans ordered to evaluate for appendicitis and less absolute diagnoses of appendicitis made, there was a higher overall positive percentage of studies, and that positive studies were associated with more severe findings in their study period (42 days) compared to control [16]. Snapiri et al. reported a seven-case series in their institution in Israel in which pediatric patients presented with complicated appendicitis, which they identified to be secondary to a combination of factors, including parental concern, use of telemedicine, and insufficient clinical evaluation [17]. Finally, O'Brien et al., a group out of Toronto, Canada, evaluated the impact of the COVID-19 pandemic on presentations to the emergency department for acute abdominal complaints and found that there was both an increased positive CT scan rate and an increased rate of complications without significant differences in surgical interventions. Rates of admission and nonsurgical interventions were not reported. Of note, the daily case burden of COVID-19 in Toronto during their study period was not specified [18].

In this study, we (1) compare the utilization of CT scans of the abdomen and pelvis ordered from the ED at a healthcare system under non-surge conditions during April 2020 vs. April 2019, (2) assess the percent positive rate of these CT scans, and (3) compare subsequent patient disposition and rates of procedural intervention as a metric of acuity at presentation.

\section{Material and methods}

We carried out a retrospective cohort study with data collected from two emergency departments associated with the University of Utah healthcare system from April 1 to April 30, 2020. This time period was chosen as it represented the nadir month of ED visits due to the COVID-19 pandemic at our institution. Subsequently, the same data was compiled over the corresponding time period during April 2019 to serve as the control cohort for our study.

Initial data was collected comparing the number of visits to the University of Utah healthcare system emergency departments during the above time periods. Of those visits, the number of patients presenting with abdominal pain, flank pain, and nausea and/or vomiting was compared between 2020 and 2019 as a baseline for our study.

CT scans of interest were identified by use of Nuance mPower Clinical Analytics (Nuance Communications, Inc., Burlington, MA, USA). Selection criteria for CT scans include imaging studies ordered from the University of Utah healthcare system emergency departments from April 1 at 00:00 through April 30 at 23:59 in 2019 and 2020 on patients $\geq 18$ years of age at time of study using the following study types: CT abdomen and pelvis, CT abdomen; CTA abdomen and pelvis, and $\mathrm{CT}$ of the pelvis; studies with, without, or with and without IV contrast; and studies with or without oral contrast. Exclusion criteria include studies ordered for trauma which met trauma team activation on arrival to the hospital and CTs of the pelvis which were performed to evaluate the bony pelvis for traumatic injuries. The presenting chief complaints of those patients corresponding to the above CT scans were compiled and analyzed.

The reports of the identified studies were collaboratively reviewed by two independent physicians: an emergency medicine physician and a radiologist. Studies were then classified as positive or negative when an agreement on designation was reached. In attempting to classify whether a CT had a positive or negative finding, the authors collaboratively reviewed each chart and utilized all accessible data including physician notes, radiology report, laboratory data, operative and intervention reports, pathology results, and additional non-CT confirmatory imaging during patient visit. A conclusion was then made with regard to the appropriate classification. There were several cases where the same radiological impression would be considered positive or negative dependent on data gathered external to the radiology report.

Consider the case of the CT finding of "urinary bladder wall thickening" (Fig. 1). If the patient had evidence based on physical exam, clinical diagnosis, or urinalysis of cystitis, this would then be labeled a positive study for cystitis (Fig. 1a). If, however, the patient had no evidence of urinary tract infection, an exam inconsistent with cystitis, or an alternative clinical diagnosis, this was determined to be a negative study for cystitis (Fig. 1b). We felt this would be more clinically and practically accurate compared to using natural language processing (NLP) or other modality to analyze radiology reports given nonstandard reporting habits. For those patients with a positive CT finding, the electronic medical record was reviewed to assess patient disposition, admission location, interventions performed during admission, and in-hospital mortality.

Of those scans demarcated as negative, there were three subsets of CT scans identified: first, scans in which no findings were found; second, scans in which impressionable findings were present, but which were not felt to explain the patients' symptomatology (e.g., a hiatal hernia in a patient with dysuria); and third, scans in which incidental findings were present but which are not symptomatic (e.g., an adrenal adenoma).

Chi-squared categorical testing was conducted to determine differences between positive and negative rates of CT imaging as well as differences between specific diagnoses, admission status, and interventions. Statistical significance was considered when $p<.05$. 
Fig. 1 Two examples of the CT finding of "urinary bladder wall thickening". a Axial CT images of the urinary bladder of a 27 year-old female patient who presented with flank pain. This scan was designated positive for the diagnosis of cystitis. b Axial CT images of the urinary bladder of a 68-year-old male patient who presented with right upper quadrant pain. This scan was designated negative for the diagnosis of cystitis

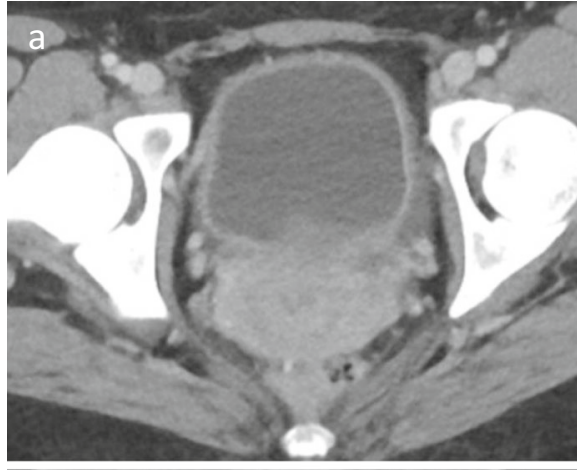

\begin{tabular}{|c|c|}
\hline Radiology Report & $\begin{array}{l}\text { "Diffuse urinary bladder wall thickening and } \\
\text { perivesicular fat stranding." }\end{array}$ \\
\hline Select Vitals & Temperature $38.2^{\circ} \mathrm{C}$ \\
\hline Urinalysis/Culture & $\begin{array}{l}\text { UA appearance: Cloudy } \\
\text { Leukocyte Esterase: Large } \\
\text { Nitrite: Positive } \\
\text { WBC: }>182 \\
\text { Bacteria: Few } \\
\text { Urine Culture: > 100,000 cfu/mL E. coli }\end{array}$ \\
\hline Hematology & WBC 13.16k \\
\hline ED Diagnosis & $\begin{array}{l}\text { Cystitis } \\
\text { Pyelonephritis }\end{array}$ \\
\hline Radiology Report & $\begin{array}{l}\text { "Diffuse bladder wall thickening, which may } \\
\text { be related to chronic outflow obstruction." }\end{array}$ \\
\hline Select Vitals & Temperature $36.7^{\circ} \mathrm{C}$ \\
\hline Urinalysis/Culture & $\begin{array}{l}\text { UA appearance: Clear } \\
\text { Leukocyte Esterase: Negative } \\
\text { Nitrite: Negative } \\
\text { WBC: } 1 \\
\text { Bacteria: None } \\
\text { Urine Culture: N/A }\end{array}$ \\
\hline Hematology & WBC 11.61k \\
\hline ED Diagnosis & $\begin{array}{l}\text { Heart Failure, diastolic, acute } \\
\text { Shock Liver } \\
\text { Hyperkalemia }\end{array}$ \\
\hline
\end{tabular}

\section{Results}

There was a decrease of overall visits to the ED in April 2020 compared to April 2019 by 1475 visits (3550 and 5025 visits respectively), equating to a $29.4 \%$ decrease (Table 1, Fig. 2). The most common presenting chief complaints related to the abdomen and pelvis of all ED presentations during these two comparative months were similar; abdominal pain ( $10.0 \%$ vs. $10.4 \%)$, nausea and/or vomiting (3.1\% vs. $4.8 \%)$, and flank pain (2.2\% vs. $2.5 \%)$ in 2020 and 2019 respectively (Table 2 ).

Table 1 Demographic information, including the total number of ED visits, CT scans of the abdomen and pelvis performed from the ED, and age and gender data of those patients who underwent $\mathrm{CT}$ scans

\begin{tabular}{lll}
\hline & April 2020 & April 2019 \\
\hline Total ED visits & 3550 & 5025 \\
CT scans performed & 385 & 563 \\
Gender & $\%(n=)(p=0.695)$ & \\
Female & $56.6 \%(218)$ & $57.9 \%(326)$ \\
Male & $43.4 \%(167)$ & $42.1 \%(237)$ \\
Age (years) & Median (IQR) & \\
& $47(25)$ & $49(27)$ \\
Age group & $n=$ & \\
$18-40$ & 137 & 207 \\
$41-60$ & 153 & 203 \\
$61-80$ & 71 & 122 \\
$81+$ & 24 & 31 \\
\hline
\end{tabular}

There was a decrease in CT scans of the abdomen and pelvis in 2020 compared to 2019,385 from 563 scans respectively, equating a decrease of $31.6 \%$ (Fig. 2). CT scans were performed from the ED at a similar rate in our study period (10.8\%) compared to 2019 (11.2\%). Of patients undergoing CT scans of the abdomen and pelvis in 2020 vs. 2019 , there were no demographic differences between gender $(56.6 \%$ and $57.9 \%$ female) and age (median age 47 [IQR 25] and 49 [IQR 27]) respectively (Table 1). The most common presenting chief complaints of those patients undergoing CT scans of the abdomen and pelvis during these two comparative months were similar; abdominal pain (59.0\% vs. $50.4 \%)$, flank pain ( $12.5 \%$ vs. $11.2 \%)$, and nausea and/or vomiting (9.6\% vs. $9.4 \%$ ) in 2020 and 2019 respectively (Table 2). A comprehensive list of chief complaints can be found in more detail in Table 5. Of note, we identified more chief complaints than CT scans preformed as some patients presented with multiple complaints.

We found a statistically significant higher percentage of positive CT findings in April 2020 compared to April 2019, $58.2 \%$ compared to $50.8 \%(p=0.025)$ respectively. We identified three diagnoses in which a statically significant difference was observed between our cohorts: appendicitis (5.5\% and $2.3 \%, p=0.011)$, colitis $(4.7 \%$ and $2.3 \%, p=0.044)$, and cholangitis $(1.3 \%$ and $0.2 \%, p=0.033)$ in descending order of frequency. Differences between the remaining diagnoses were not statistically significant. Table 3 can be referenced for a comparison of common diagnoses with a full list of diagnoses listed in Table 6. It should be noted that there were occasionally multiple diagnoses per $\mathrm{CT}$ scan performed. 
Table 2 Three most common abdominal chief complaints from all ED visits in April 2020 compared to April 2019. The 15 most common chief complaints associated with ED visits which resulted in CT scans of the abdomen and pelvis in 2020 compared to 2019 . The complete list of chief complaints can be found in Table 5 (IUD intrauterine device)

\begin{tabular}{|c|c|c|}
\hline Chief complaints & April 2020 & April 2019 \\
\hline Total ED visits & $\%(n)$ & \\
\hline Abdominal pain & $10.0(292)$ & $10.4(446)$ \\
\hline Nausea and/or vomiting & $3.1(89)$ & $4.8(204)$ \\
\hline Flank pain & $2.2(64)$ & $2.5(105)$ \\
\hline CT scans & $\%(n)$ & \\
\hline Abdominal pain & $59.0(227)$ & $50.4(284)$ \\
\hline Flank pain & $12.5(48)$ & $11.2(63)$ \\
\hline Nausea and/or vomiting & $9.6(37)$ & $9.4(53)$ \\
\hline Chest pain & $4.2(16)$ & $4.6(26)$ \\
\hline Fever & $3.6(14)$ & $2.5(14)$ \\
\hline Shortness of breath & $2.9(11)$ & $2.7(15)$ \\
\hline Dysuria, hematuria, or urinary retention & $2.6(10)$ & $3.6(20)$ \\
\hline Rectal pain, rectal bleeding, or hemorrhoids & $2.3(9)$ & $1.8(10)$ \\
\hline Altered mental status & $1.8(7)$ & $2.1(12)$ \\
\hline Back pain & $1.8(7)$ & $2.7(15)$ \\
\hline Constipation & $1.8(7)$ & $1.4(8)$ \\
\hline Diarrhea & $1.8(7)$ & $2.1(12)$ \\
\hline Pelvic pain, vaginal bleeding, or IUD concerns & $1.6(6)$ & $2.0(11)$ \\
\hline Abscess, fistula, or skin infection & $1.3(5)$ & $2.1(12)$ \\
\hline Cough & $1.3(5)$ & $1.1(6)$ \\
\hline
\end{tabular}

There were 161 and 277 negative scans identified in 2020 and 2019, respectively. Of these, there were 31 and 75 scans identified in 2020 and 2019 which had findings in the impression which were not felt to explain the patients' symptomatology $(p=0.091)$. There were 48 and 81 scans with incidental findings in 2020 and 2019 respectively ( $p=0.899$ ). Grouped analyses of these two subsets were also not significant across time points $(p=$ 0.180).

Admissions in those undergoing CT imaging were increased in April 2020 when compared to 2019: 40.8\% vs. $34.1 \%(p=0.036)$. However, we found no difference in
Fig. 2 A comparison of total visits to the emergency department in 2020 vs. 2019 (evaluated using the left axis), and a comparison of total CT scans performed in 2020 vs. 2019 with a ratio of positive to negative $\mathrm{CT}$ scan results (evaluated using the right axis)

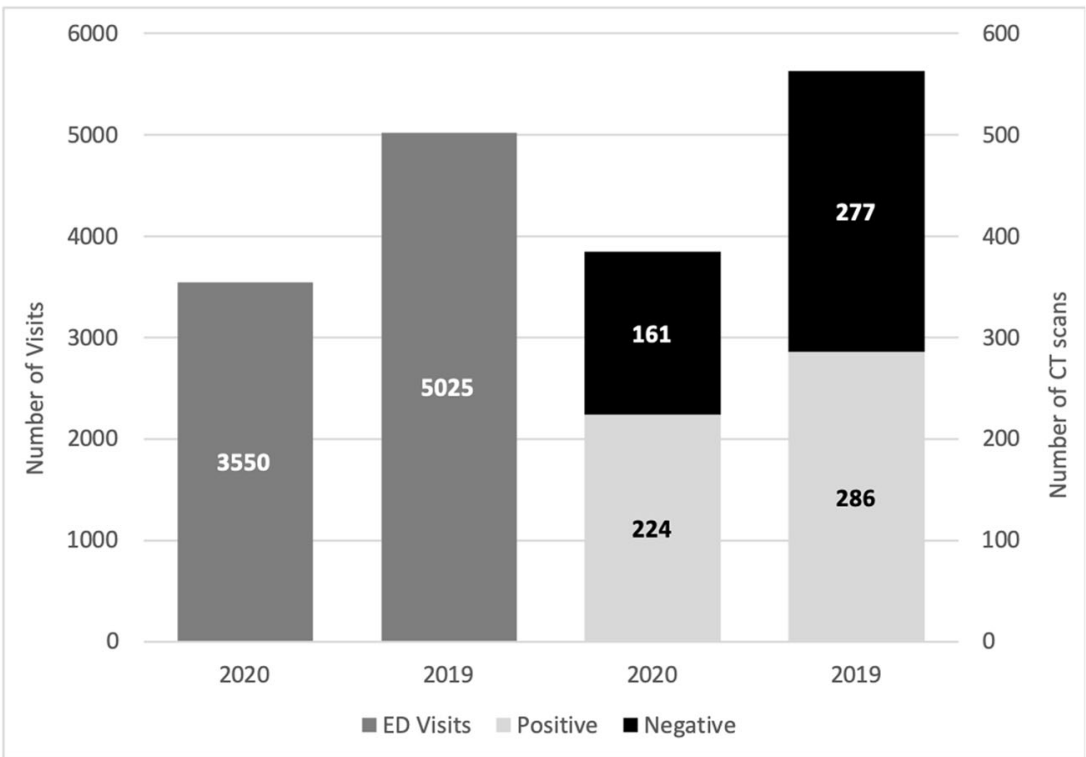


Table 3 A selection of common diagnoses in 2020 compared to 2019. Diagnoses were included in this table if they were identified in five or more cases in 2020. The complete list of diagnoses can be found in Table 6

\begin{tabular}{llll}
\hline Diagnoses & April 2020 & April 2019 & \\
\hline & $\%(n)$ & & $p$-value \\
Positive CT findings & $58.2(224)$ & $50.8(286)$ & $0.025^{*}$ \\
Abscess & $2.6(10)$ & $3.6(20)$ & 0.409 \\
Appendicitis & $5.5(21)$ & $2.3(13)$ & $0.011^{*}$ \\
Ascites & $1.6(6)$ & $0.7(4)$ & 0.209 \\
Bowel obstruction & $4.9(19)$ & $5.0(28)$ & 0.979 \\
Cholangitis & $1.3(5)$ & $0.2(1)$ & $0.033^{*}$ \\
Cholecystitis & $1.3(5)$ & $1.2(7)$ & 0.94 \\
Cirrhosis & $2.3(9)$ & $0.5(3)$ & 0.268 \\
Colitis & $4.7(18)$ & $2.3(13)$ & $0.044^{*}$ \\
Cystitis & $1.6(6)$ & $2.5(14)$ & 0.329 \\
Diverticulitis & $3.9(15)$ & $3.1(17)$ & 0.463 \\
Enteritis & $2.1(8)$ & $1.8(10)$ & 0.738 \\
Neoplasm/metastases & $2.3(9)$ & $2.7(15)$ & 0.802 \\
Ovarian cyst/mass & $2.9(11)$ & $1.8(10)$ & 0.267 \\
Pancreatitis & $2.6(10)$ & $1.6(9)$ & 0.281 \\
Perianal/perirectal abscess & $1.3(5)$ & $1.1(6)$ & 0.742 \\
Pyelitis/pyelonephritis & $2.9(11)$ & $1.6(9)$ & 0.185 \\
Ureterolithiasis & $10.7(41)$ & $9.2(52)$ & 0.473 \\
\hline
\end{tabular}

Statstistical significance was considered with $p<.05$ rates of admissions to the intensive care unit (ICU) over our study period compared to control $(8.9 \%$ compared to $9.9 \%)$. Interventions of any kind were similar between the two cohorts: $22.1 \%$ in 2020 vs. $21.3 \%$ in 2019 ( $p=$ $0.779)$. Subset analysis did not demonstrate a significant difference in rates of specific interventions, even when controlling for positive CT findings. Mortality rates of patients undergoing $\mathrm{CT}$ scans were similar regardless of positive CT status, $n=4$ in both cohorts with a rate of $1.0 \%$ and $0.7 \%$ in 2020 and 2019 respectively (Table 4).

\section{Discussion}

In comparison of April 2020 to April 2019, there was a similar percentage decrease in overall visits to the ED (29.4\% decrease) and CT scans of the abdomen and pelvis performed from the ED (31.6\% decrease) (Fig. 2). However, we found a significantly higher percentage of positive CT scans as well as a higher overall admission rate. We predict that the majority of patients who theoretically had abdominal complaints but did not present to the ED during our study period would have had either a negative CT scans or a CT scan with findings not requiring admission or procedural interventions and surmise that such self-selection was the fundamental diver for our findings.
Table 4 Outcomes in 2020 compared to 2019, including overall admission rate, admission to the medical and surgical floors or the ICU, procedural interventions and subset analysis, and mortality rate. Rates of interventions were calculated as a percentage of positive CT scans. No difference was seen when calculated as a percentage of all CT studies performed (ERCP endoscopic retrograde cholangiopancreatography; $I C U$ intensive care unit)

\begin{tabular}{|c|c|c|c|}
\hline Outcomes & April 2020 & April 2019 & \\
\hline & $\%(n)$ & & $p$-value \\
\hline Admissions & $40.8(157)$ & $34.1(192)$ & $0.036^{*}$ \\
\hline Floor (medical and surgical) of all admissions & $91.1(143)$ & $90.1(173)$ & 0.756 \\
\hline Floor (medical and surgical) of all CT scans & $37.1(143)$ & $30.7(173)$ & $0.040^{*}$ \\
\hline Floor (medical and surgical) of all positive CTs & $49.1(110)$ & $45.5(130)$ & 0.410 \\
\hline ICU of all admissions & $8.9(14)$ & $9.9(19)$ & 0.320 \\
\hline ICU of all CT scans & $3.6(14)$ & $3.4(19)$ & 0.829 \\
\hline \multirow[t]{2}{*}{ ICU of all of all positive CTs } & $4.9(11)$ & $5.2(15)$ & 0.865 \\
\hline & $\%(n)$ & & $p$-value \\
\hline Procedural intervention & $38.0(85)$ & $42.0(120)$ & 0.359 \\
\hline Operative intervention & $20.5(46)$ & $23.1(66)$ & 0.491 \\
\hline Percutaneous drain or intervention & $5.8(13)$ & $9.8(28)$ & 0.100 \\
\hline ERCP & $0.5(1)$ & $1.1(3)$ & 0.444 \\
\hline Bedside intervention & $2.2(5)$ & $1.8(5)$ & 0.696 \\
\hline Endoscopy or colonoscopy & $4.5(10)$ & $5.6(16)$ & 0.565 \\
\hline Paracentesis/thoracentesis & $3.6(8)$ & $1.4(4)$ & 0.181 \\
\hline Percutaneous enteric tube & $0.5(1)$ & $1.4(4)$ & 0.279 \\
\hline Endovascular intervention & $0.0(0)$ & $1.4(4)$ & - \\
\hline \multirow[t]{2}{*}{ Unknown and/or transferred } & $0.5(1)$ & $0.0(0)$ & - \\
\hline & $\%(n)$ & & $p$-value \\
\hline Overall mortality & $1.0(4)$ & $0.7(4)$ & 0.587 \\
\hline In-hospital mortality & $2.5(4)$ & $2.1(4)$ & 0.773 \\
\hline
\end{tabular}

Statstistical significance was considered with $p<.05$ 
O'Brien et al. recently published an article addressing a similar hypothesis as our analysis; however, our study has a number of important comparative differences and relative strengths. First, our study was conducted in the USA compared to Canada. There are intrinsic differences of the healthcare system between the two countries, including ED utilization, limiting the application of such a study in the US setting. Our methodology also benefits from a multidisciplinary and multifactorial approach to data analysis, as our data analysis was performed by both an emergency medicine physician and a radiologist and considered a totality of data available in the EMR, in contrast to one specialty considering only imaging and operative reports. Finally, our study evaluated not only surgical operations as metrics of acuity, but also a host of other outcomes, including admission data and nonsurgical interventions. This notable difference is evident as they cite only 20 and 5 surgical interventions in the 213 and 240 patients with positive CT scans in 2020 and 2019 respectively, corresponding to a $9.4 \%$ and $2.1 \%$ surgical intervention rate. Compare this to the surgical intervention rate in those patients found to have positive CT findings in our study, $20.5 \%$ and $23.1 \%$ in 2020 and 2019 respectively. The marked differences in our surgical rates may reflect the threshold needed to be met in order to classify a CT scan as positive under our methodology. Differing practice habits across countries and healthcare systems could compound such discrepancies.

Contrary to Romero et al., we found a statistically significant increase in absolute cases of appendicitis during the pandemic period (21 in 2020 vs. 13 in 2019) with an associated increase in percentage of acute appendicitis diagnosed on CT (5.5\% in 2020 vs. $2.3 \%$ in 2019). In the case of appendicitis, our sample size was too small to discuss rates of perforation or complications of potential delayed presentations, as only one case of perforated appendicitis was identified in each cohort. Statistical difference was also obtained in two other diagnoses, colitis and cholangitis, which previously have not been described. Otherwise, the rate of diagnosis on positive CT findings was essentially equivocal in the two cohorts. Additionally, we did not see a higher rate of ICU admission, operative intervention, or in-hospital mortality to suggest increased acuity at presentation, even controlling for positive CT findings.

We believe that decreased number of CT scans performed in the ED for abdominal complaints likely represents the consequence of improved patient self-selection with higher threshold for ED visits. The healthcare system in which this study was performed is located in a state which did not have mandated lockdowns and did not see a significant increase in COVID-19 patients until later in the year. The average rate of COVID-19 cases per day over the month of April 2020 was approximately 126
(3.93 cases per 100,000 population) in Utah (3785 new cases total (118.06 per 100,000 population) in April 2020), compared to 7796 daily cases (40.08 cases per 100,000 population) in New York (233,893 new cases total (1202.53 per 100,000 population) April 2020), which was the hardest hit state of the pandemic in the USA at that time [19, 20]. Fear of accessing the healthcare system has previously been suggested as a motivating factor for patients when explaining decreased ED utilization [21, 22]. Changes in workflow, however, have also been implicated in such decreases, including following the opening of walk-in clinics $[23,24]$ or the use of self-screening forms [25]. The cumulative effect of such modifications to our health system is difficult to assess given the heterogeneous strategies and different medical specialties employed in reaction to the pandemic.

An assumption of our study was that higher acuity presentation necessitated increased admissions and interventions, both operative and nonoperative. While we found an increase in admission rates between our cohorts (40.8\% and $34.1 \%$ in 2020 and 2019 respectively, $p=$ 0.036 ), we did not find a difference in interventions or admissions to the ICU, suggesting no difference in acuity at time of presentation. However, concern for resource preservation has been shown globally to impact admission habits [26], operative decisions [27, 28], and aerosolizing procedures such as endoscopies [29]. We surmise that standards for admission in 2020 were at least equal to or more strenuous than in 2019 , due to the underlying concerns of potential resource limitations; however, the contribution of such provider concern on the outcomes of our patient cohort is unclear.

Overall, our study suggests that there was a decrease in patient visits without undo consequence on severity of patient pathology in a region undergoing non-surge conditions. This supports an argument from an editorial penned by Moynihan et al., in which the authors call for sustaining the trends seen during the COVID-19 pandemic as a means to reduce unnecessary healthcare utilization in order to better tackle the difficult issues of sustainability and equity plaguing healthcare [30]. Such appropriate decreases may also increase the efficiency of the healthcare system for patients, decreasing time to diagnosis, and improving ED throughput [31]. Importantly, the decreased percentage of CT scans performed between our study group and the control cohort is suggestive that such reduction in healthcare utilization may result in a decreased rate of negative CT scans, therefore decreasing overall population-based medical radiation.

Importantly, our data does not take into account patient presentations that would have benefited from ED evaluation regardless of CT imaging or admission status, i.e., for the administration of antibiotics. The effect of the 
pandemic on this patient population is unknown and outside the scope of this study. Furthermore, while we do not demonstrate increased harm to patients with abdominal complaints in this study, the negative impacts of decreased healthcare utilization have been described for non-abdominal pathology. For example, multiple studies have demonstrated delayed stroke presentation [32] and increased time to mechanical thrombectomy for embolic stroke [33] during pandemic conditions. For this reason, we are reticent to generalize our results to non-abdominal pathology or to abdominal pathology in patients undergoing surge pandemic conditions. Ultimately, comprehensive consequences of the COVID-19 pandemic are still to be determined.

The authors used clinical judgment to integrate a totality of information gathered from the electronic medical record in determination of classification of CT findings as positive or negative. This may have resulted in inappropriate classifications in either direction. We felt, however, that individual review of every included patient would lead to a more accurate assessment of findings compared to NLP or other modality for radiological report review. It should be noted there was no statistically significant difference between our time periods with regard to CT scans that were called negative. This is additionally true when considering those scans in which a positive finding was identified, but in which such findings were not felt to explain the patient's symptomatology, and in scans in which an incidental, clinically occult finding was identified. Such analysis suggests the authors did not unintentionally bias the study with a disproportionate number of positive studies in either cohort.

There are several limitations to our study. Given this study sample represented a single healthcare system, results may not be generalizable to healthcare systems at large, particularly given the difference in COVID-19 disease burden and government restrictions on public activity. Second, it is possible patients presented to other regional hospitals not within the studied healthcare system and therefore would not be captured in our analysis. Finally, while the number of CT scans performed in each cohort was powered to detect a difference in overall rates of diagnoses, the ambiguity and diversity of radiologic linguistic terminology resulted in many varied diagnoses. To minimize bias, the authors limited interpretation of the radiographic impression, and adhered to the terminology in the report as much as possible. As such, diagnoses which reached or did not reach statistical significance by a small margin may have reflected variability in verbiage and not true differences in pathology. Similarly, given our relatively low numbers for each specific diagnosis, we are unable to draw any conclusions regarding diagnosis-specific interventions or complications. Finally, we lack comparison of overall mortality between our study periods for the population sampled. Such data is unavailable to the authors as the medical center in question is a large tertiary care center with a significant catchment area which extends into multiple neighboring states.

The model of emergency department use established in this pandemic may result in decreased population radiation dose, increased ED throughput, and decreased timeto-diagnosis in patients with abdominal pathology requiring admission or intervention. Further investigations should work to analyze additional cohorts under similar conditions in order to further elucidate small differences in complications and interventions, as well as evaluate diagnosis-specific patterns. Additional studies targeting medical interventions should also be pursued as to minimize the risk of missing patients in which our outcomes are not applicable.

\section{Conclusions}

We found that while there were fewer CT scans of the abdomen and pelvis ordered from the emergency department in April 2020 compared to the same time period in 2019, there was a higher percentage of positive CT scans and an overall higher admission rate. Using the metrics of positive CT scans, admission, and procedural intervention, our findings are suggestive that there was an appropriate decrease in patient emergency department visits during our study period, driven by pre-hospital self-selection. We also did not see a higher rate of overall ICU admission, operative intervention, or inhospital mortality to suggest that our healthcare system was missing patients with advanced pathology. Together, these findings propose that there was a decrease in unnecessary healthcare utilization regarding CT scans obtained to work up abdominal complaints without increased harm to patients due to delayed presentations.

Availability of data and material Not applicable.

Author contributions $\mathrm{AG}$ and $\mathrm{CK}$ performed the data collection and analysis. AG, CK, AS, and $\mathrm{PO}$ were responsible for the draft production and editing. AG was responsible for the submission.

\section{Declarations}

Ethics approval Institutional Review Board (IRB) exempt.

Consent to participate Not applicable, retrospective study.

Consent for publication Not applicable, retrospective study.

Conflict of interest The authors declare that they have no conflict of interest.

Code availability Not applicable. 


\section{Appendix 1}

Table 5 Comprehensive list of chief complaints of those patients who underwent CT scans in 2020 compared to 2019

\begin{tabular}{|c|c|c|c|c|c|}
\hline Chief complaint & 2020 & 2019 & Chief complaint & 2020 & 2019 \\
\hline Abdominal pain, swelling, cramping & 227 & 284 & Hand injury & 1 & 0 \\
\hline Abnormal lab test & 2 & 2 & Headache & 0 & 4 \\
\hline Abscess/fistula/skin infection & 5 & 12 & Hernia & 2 & 3 \\
\hline Alcohol/drug/ingestion & 3 & 2 & Hyperglycemia & 0 & 3 \\
\hline Allergic reaction & 0 & 2 & Hypertension & 0 & 1 \\
\hline Altered mental status & 7 & 12 & Hypotension & 2 & 3 \\
\hline Anxiety & 1 & 2 & Hypoxemia & 1 & 1 \\
\hline Aspiration/pneumonia & 1 & 1 & Leg pain/swelling & 4 & 8 \\
\hline Back pain & 7 & 15 & Loss of consciousness & 2 & 2 \\
\hline Behavioral change & 1 & 0 & Malaise & 0 & 1 \\
\hline Body aches/generalized pain & 4 & 2 & Melena & 1 & 0 \\
\hline Bowel obstruction & 0 & 1 & Nausea and vomiting & 37 & 53 \\
\hline Bruising & 1 & 0 & Neck pain & 0 & 2 \\
\hline Chest pain & 16 & 26 & None & 1 & 0 \\
\hline Chills & 0 & 1 & Palpitations & 0 & 1 \\
\hline Cirrhosis/jaundice & 4 & 5 & Pancreatitis & 1 & 1 \\
\hline Confusion & 0 & 2 & Pelvic pain/vaginal bleeding & 6 & 11 \\
\hline Constipation & 7 & 8 & Postoperative pain & 3 & 10 \\
\hline Cough & 5 & 6 & Puncture wound & 0 & 1 \\
\hline Crisis/suicidal & 2 & 3 & Rash & 1 & 0 \\
\hline Cyst & 0 & 1 & Rectal pain/bleeding & 9 & 10 \\
\hline Dialysis & 1 & 1 & Rib pain & 0 & 1 \\
\hline Diarrhea & 7 & 12 & Right lower quadrant pain & 0 & 1 \\
\hline Dizziness & 3 & 7 & Seizure/shaking & 2 & 3 \\
\hline Dysuria/hematuria/urinary retention & 10 & 20 & Shortness of breath & 11 & 15 \\
\hline Edema & 1 & 0 & Sore throat & 1 & 0 \\
\hline Failure to thrive & 1 & 0 & Speech problem & 0 & 1 \\
\hline Fall & 2 & 1 & STD screen & 0 & 1 \\
\hline Fatigue & 3 & 9 & Tachycardia & 0 & 2 \\
\hline Fever & 14 & 14 & Tailbone pain & 1 & 0 \\
\hline Flank pain & 48 & 63 & Tingling & 0 & 1 \\
\hline Foley catheter care & 1 & 0 & Tube care & 3 & 9 \\
\hline Follow-up & 0 & 1 & Tumor evaluation & 0 & 2 \\
\hline Genital pain/groin swelling & 3 & 10 & Vision changes & 0 & 1 \\
\hline GERD/GI problem & 0 & 2 & Weakness & 1 & 2 \\
\hline
\end{tabular}




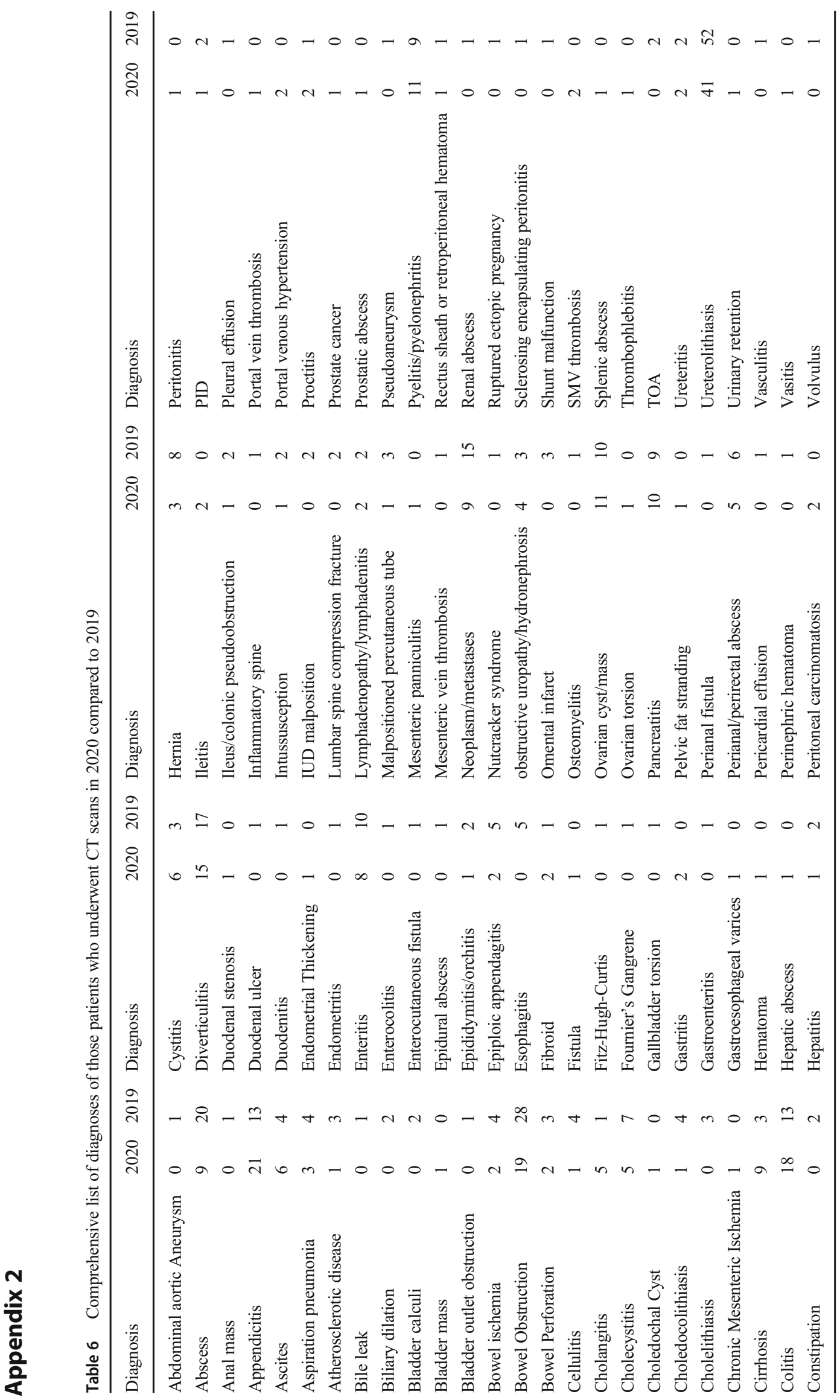




\section{References}

1. Hartnett, K. P., Kite-Powell, A., DeVies, J., Coletta, M. A., Boehmer, T. K., Adjemian, J., et al. (2020). Impact of the COVID-19 pandemic on emergency department visits-United States, January 1, 2019-May 30, 2020. MMWR Morb Mortal Wkly Rep, 69(23), 699-704. 10.15585/mmwr.mm6923e1.

2. Houshyar R, Tran-Harding K, Glavis-Bloom J, Nguyentat M, Mongan J, Chahine C, Loehfelm TW, Kohli MD, Zaragoza EJ, Murphy PM, Kampalath R (2020) Effect of shelter-in-place on emergency department radiology volumes during the COVID-19 pandemic. Emerg Radiol 27:1-4. https://doi.org/10.1007/s10140020-01797-y

3. Jeffery MM, D'Onofrio G, Paek H, Platts-Mills TF, Soares WE 3rd, Hoppe JA et al (2020) Trends in emergency department visits and hospital admissions in health care systems in 5 states in the first months of the COVID-19 pandemic in the US. JAMA Intern Med. 180:1328-1333. https://doi.org/10.1001/jamainternmed.2020.3288

4. Kim HS, Cruz DS, Conrardy MJ, Gandhi KR, Seltzer JA, Loftus TM, Fant AL, McCarthy DM (2020) Emergency department visits for serious diagnoses during the COVID-19 pandemic. Acad Emerg Med. 27:910-913. https://doi.org/10.1111/acem.14099

5. Aljuboori Z, Sieg E (2020) The early effects of social distancing resultant from COVID-19 on admissions to a Level I trauma center. Injury. 51:2332. https://doi.org/10.1016/j.injury.2020.06.036

6. Garcia S, Albaghdadi MS, Meraj PM, Schmidt C, Garberich R, Jaffer FA, Dixon S, Rade JJ, Tannenbaum M, Chambers J, Huang PP, Henry TD (2020) Reduction in ST-segment elevation cardiac catheterization laboratory activations in the United States during COVID-19 pandemic. J Am Coll Cardiol 75(22):28712872. https://doi.org/10.1016/j.jacc.2020.04.011

7. Desai SM, Guyette FX, Martin-Gill C, Jadhav AP (2020) Collateral damage-impact of a pandemic on stroke emergency services. J Stroke Cerebrovasc Dis 29(8):104988. https://doi.org/10.1016/j. jstrokecerebrovasdis.2020.104988

8. Hsiao, J., Sayles, E., Antzoulatos, E., Stanton, R. J., Sucharew, H., Broderick, J. P., et al. (2020). Effect of COVID-19 on emergent stroke care: a regional experience. Stroke, Strokeaha120030499. https://doi.org/10.1161/strokeaha.120.030499.

9. Kansagra AP, Goyal MS, Hamilton S, Albers GW (2020) Collateral effect of Covid-19 on stroke evaluation in the United States. N Engl J Med. 383:400-401. https://doi.org/10.1056/NEJMc2014816

10. Navarro RA, Reddy NC, Weiss JM, Yates AJ, Fu FH, McKee M, Lederman ES (2020) Orthopaedic systems response to and return from the COVID-19 pandemic: lessons for future crisis management. J Bone Joint Surg Am 102(14):e75. https://doi.org/10.2106/ JBJS. 20.00709

11. Kamine TH, Rembisz A, Barron RJ, Baldwin C, Kromer M (2020) Decrease in trauma admissions with COVID-19 pandemic. West $\mathrm{J}$ Emerg Med 21(4):819-822. https://doi.org/10.5811/westjem.2020. 5.47780

12. Chaiyachati, B. H., Agawu, A., Zorc, J. J., \& Balamuth, F. (2020). Trends in pediatric emergency department utilization after institution of COVID-19 mandatory social distancing. J Pediatr. https:// doi.org/10.1016/j.jpeds.2020.07.048

13. Kenyon, C. C., Hill, D. A., Henrickson, S. E., Bryant-Stephens, T. C., \& Zorc, J. J. (2020). Initial effects of the COVID-19 pandemic on pediatric asthma emergency department utilization. J Allergy Clin Immunol Pract. https://doi.org/10.1016/j.jaip.2020.05.045

14. Walker DM, Tolentino VR (2020) COVID-19: the effects on the practice of pediatric emergency medicine. Pediatr Emerg Med Pract 17(Suppl 6-3):1-15

15. Levine DA, Fraymovich S, Platt SL (2020) Where have all the children gone? Pediatric perspectives on COVID-19 in New York
City. Ann Emerg Med 76(1):109-110. https://doi.org/10.1016/j. annemergmed.2020.04.035

16. Romero J, Valencia S, Guerrero A (2020) Acute appendicitis during coronavirus disease 2019 (COVID-19): changes in clinical presentation and CT findings. J Am Coll Radiol 17(8):1011-1013. https://doi.org/10.1016/j.jacr.2020.06.002

17. Snapiri O, Rosenberg Danziger C, Krause I, Kravarusic D, Yulevich A, Balla U, Bilavsky E (2020) Delayed diagnosis of paediatric appendicitis during the COVID-19 pandemic. Acta Paediatr 109(8):1672-1676. https://doi.org/10.1111/apa.15376

18. O'Brien CM, Jung K, Dang W, Jang HJ, Kielar AZ (2020) Collateral damage: the impact of the COVID-19 pandemic on acute abdominal emergency presentations. J Am Coll Radiol 17(11): 1443-1449. https://doi.org/10.1016/j.jacr.2020.08.010

19. New York State Department of Health COVID-19 Tracker. Available at: https://covid19tracker.health.ny.gov/views/NYSCOVID19-Tracker/NYSDOHCOVID-19Tracker-Map. Accessed September 15, 2020.

20. Utah Department of Health COVID-19 Surveillance. Available at https://coronavirus.utah.gov/case-counts/. Accessed September 15, 2020.

21. Vanni, G., Materazzo, M., Pellicciaro, M., Ingallinella, S., Rho, M., Santori, F., et al. (2020). Breast cancer and COVID-19: the effect of fear on patients' decision-making process. In Vivo, 34(3 Suppl), 1651-1659. 10.21873/invivo.11957.

22. Mantica G, Riccardi N, Terrone C, Gratarola A (2020) NonCOVID-19 visits to emergency departments during the pandemic: the impact of fear. Public Health 183:40-41. https://doi.org/10. 1016/j.puhe.2020.04.046

23. MacKechnie MC, Nadeau M, Deering E, Thaller J, MacKechnie MA (2020) Orthopaedic walk-in clinics: a model to lessen the burden on emergency departments during the COVID-19 pandemic. J Orthop 20:293-296. https://doi.org/10.1016/j.jor.2020.05.014

24. Hemingway JF, Singh N, Starnes BW (2020) Emerging practice patterns in vascular surgery during the COVID-19 pandemic. $\mathrm{J}$ Vasc Surg 72(2):396-402. https://doi.org/10.1016/j.jvs.2020.04. 492

25. Chiu, I. M., Cheng, C. Y., Zhang, H., \& Lin, C. R. (2020). Selfscreening to reduce medical resource consumption facing the COVID-19 pandemic. Emerg Med J (p. 255). https://doi.org/10. 1136/emermed-2020-209647.

26. Azoulay É, Beloucif S, Guidet B, Pateron D, Vivien B, Le Dorze M (2020) Admission decisions to intensive care units in the context of the major COVID-19 outbreak: local guidance from the COVID-19 Paris-region area. Crit Care 24(1):293. https://doi.org/10.1186/ s13054-020-03021-2

27. Cano-Valderrama O, Morales X, Ferrigni CJ, Martín-Antona E, Turrado V, García A, Cuñarro-López Y, Zarain-Obrador L, Duran-Poveda M, Balibrea JM, Torres AJ (2020) Acute care surgery during the COVID-19 pandemic in Spain: changes in volume, causes and complications. A multicentre retrospective cohort study. Int J Surg 80:157-161. https://doi.org/10.1016/j.ijsu.2020.07.002

28. Kelly, M. E., Murphy, E., Bolger, J. C., \& Cahill, R. A. (2020). COVID-19 and the treatment of acute appendicitis in Ireland: a new era or short-term pivot? , Colorectal Dis (pp. 648-649). https://doi. org/10.1111/codi.15141.

29. Edwards C, Penman ID, Coleman M (2020) Gastrointestinal endoscopy during COVID-19: when less is more. Frontline Gastroenterol 11(4):256-257. https://doi.org/10.1136/flgastro-2020-101492

30. Moynihan R, Johansson M, Maybee A, Lang E, Légaré F (2020) Covid-19: an opportunity to reduce unnecessary healthcare. Bmj 370:m2752. https://doi.org/10.1136/bmj.m2752

31. Cohen BA, Wessling EG, Serina PT, Cruz DS, Kim HS, McCarthy DM, Loftus TM (2020) Emergency department operations in a large health system during COVID-19. Am J Emerg Med. https:// doi.org/10.1016/j.ajem.2020.05.097 
32. Schirmer CM, Ringer AJ, Arthur AS, Binning MJ, Fox WC, James RF, Levitt MR, Tawk RG, Veznedaroglu E, Walker M, Spiotta AM, Endovascular Research Group (ENRG) (2020) Delayed presentation of acute ischemic strokes during the COVID-19 crisis. J Neurointerv Surg 12(7):639-642. https://doi.org/10.1136/ neurintsurg-2020-016299

33. Kerleroux B, Fabacher T, Bricout N, Moïse M, Testud B, Vingadassalom S, Ifergan H, Janot K, Consoli A, Ben Hassen W, Shotar E, Ognard J, Charbonnier G, L'Allinec V, Guédon A, Bolognini F, Marnat G, Forestier G, Rouchaud A, Pop R, Raynaud N, Zhu F, Cortese J, Chalumeau V, Berge J, Escalard S, Boulouis G, Chivot C, Hanafi R, Pasco A, Girot JB, Biondi A, di Caterino F, Primikiris P, Vitale G, Bonnet L, Gariel F, Barreau X, Debruxelles S, Lucas L, Menegon P, Olindo S, Poli M, Renou P, Sagnier S, Sibon I, Veunac L, Gentric JC, Barbier C, Boulanger M, Cogez J, Guettier S, Schneckenburger R, Touze E, Delaitre M, Lebendinsky P, Musacchio M, Ricolfi F, Thouant P, Caparros F, Casolla B, Della Schiava L, Dequatre N, Henon H, Pasi M, Kazemi A, Bala F, Estrade L, Mounayer C, Saleme S, Macian-Montoro F, Eker O, Cotton F, Blanc-Lasserre K, Cakmak S, Cho TH, Derex L, Lukaszewicz AC, Mechtouff L, Nighoghossian N, Philippeau F, Riva R, Turjman F, Vallet AE, Carle X, Dory-Lautrec P, Reyre A, Hak JF, Brunel H, Benali A, Collemiche FL, Dargazanli C, Cagnazzo F, Derraz I, Arquizan C, Corti L, Costalat V, Gaillard N, Gascou G, Lefèvre PH, Mourand I, Riquelme C, Derelle AL, Gory B, Liao L, Tonnelet R, Anxionnat R, Bonnerot M, Bracard S, Braun M, Humbertjean L, Lacour JC, Mione G, Planel S, Richard S, Riou-Comte N, Schmitt E, Bourcier R, Detraz L, Desal H, Alexandre PL, Daumas-Duport B, Lenoble C, Roy M, Coskun O, di Maria F, Lapergue B, Rodesch G, Wang A, Weisenburger-Lile D, Zimatore S, Ajili N, Buard G, Evrard S, Gorza L, Gratieux J,
Leguen M, Marinier S, Pico F, Poll R, Rakotoharinandrasana H, Tassan P, Tchikviladze M, Delvoye F, Hebert S, Blanc R, Ciccio G, Desilles JP, Maier B, Mazighi M, Piotin M, Redjem H, Smajda S, Ben Maacha M, Corabianu O, de Broucker T, Ille O, Manchon E, Obadia M, Obadia M, Raynouard I, Peres R, Sabben C, Smadja D, Taylor G, Thion LA, Lecler A, Spelle L, Denier C, Caroff J, Chassin O, Spelle, Venditti L, Aymard A, Betty J, Civelli V, Eliezer M, Fantoni M, Houdart E, Labeyrie MA, Saint Maurice JP, Kalsoum E, Pacini A, Ramadane C, Tuilier T, Villain A, Clarencon F, Degos V, Elhfnawy A, Elhorany M, Lenck S, Premat K, Sourour NA, Alamowitch S, Baronnet F, Crozier S, Deltour S, Leger A, Rosso C, Deltour S, Leger A, Rosso C, Pyatigorskaya N, Rodriguez Regent C, Trystram D, Naggara O, Seners P, Turc G, Edjlali M, Agbonon R, Alotaibi M, Sonchet A, Oppenheim C, Meder JF, Benzakoun J, Legrand L, Fauché C, Velasco S, Manceau PF, Moulin SSS, Eugene F, Ferre JC, Paya C, Eugene F, Gauvrit JY, Langnier-Lemercier S, Lassale M, Raoult, Ronziere, Tracol C, Vannier S, Burel J, le Moal J, Papagiannaki C, Aggour M, Sachet M, Boutet C, Beaujeux R, Hasiu A, Manisor M, Mihoc D, Kremer S, Arteaga C, Gazzola S, Darcourt J, Cognard C, Bonneville F, Christine Januel A, Olivot JM, Raposo N, Viguier A, Bibi R, Boustia F, Herbreteau D, Maldonado I, Narata AP (2020) Mechanical thrombectomy for acute ischemic stroke amid the COVID-19 outbreak: decreased activity, and increased care delays. Stroke 51(7):2012-2017. https://doi.org/10.1161/strokeaha.120.030373

Publisher's note Springer Nature remains neutral with regard to jurisdictional claims in published maps and institutional affiliations. 